\title{
SOME INTEGRAL INEQUALITIES IN TWO INDEPENDENT VARIABLES ON TIME SCALES
}

\author{
TONGLIN WANG AND RUN XU
}

Abstract. The aim of the present paper is to investigate some integral inequalities in two independent variable on time scales, which unify and extend some integral inequalities and their corresponding discrete analogues. The inequalities given here can be used as handy tools to study the properties of certain partial dynamic equations on time scales.

Mathematics subject classification (2010): 34C10. ables.

Keywords and phrases: dynamic equations, integral inequalities, time scales, two independent vari-

\section{REFERENCES}

[1] S. HILGER, Analysis on measure chains-a unified approach to continuous and discrete calculus, Results in Mathmatics 18, 1-2 (1990), 18-56.

[2] M. Bohner, A. Peterson, Dynamic Equation on Time Scales: An Introduction with Applications, Birkhäuser. Boston, 2001.

[3] M. Bohner And A. Peterson, Eds., Advances in Dynamic Equations on Time Scales, Birkhäuser, Boston, Mass, USA, 2003.

[4] W. N. Li AND W. Sheng, Some nonlinear dynamic inequalities on time scale, Proceedings of the Indian Academy of Science.Mathematical Sciences 117, 4 (2007), 545-554.

[5] F-H. Wong, C-C. Yeh, And C-H. Hong, Gronwall inequalities on time scales, Mathematical Inequalities and Applications 9, 1 (2006), 75-86.

[6] W. N. LI, Bounds for Certain Delay Integral Inequalities on Time Scales, Journal of Inequalities and Applications 2008.

[7] W. N. LI, Bounds for Certain New Integral Inequalities on Time Scales, Advances in Difference Equations 2009 (2009), Article ID 484185, 16 pages.

[8] W. N. Li AND W. SHENG, Some nonlinear integral inequalities on time scale, Journal of Inequalities and Applications 2007 (2007), Article ID 70465, 15 pages.

[9] D. B. PAChPatTE, Explicit estimates on integral inequalities with time scales, Journal of Inequalities in Pure and Applied Mathematics 7, 4 (2006), article 143.

[10] W. N. LI, Some integral inequalities useful in the theory of certain partial dynamic equations on time scales, Computers and Mathematics with Applications 61 (2011), 1754-1759.

[11] Fan Wei Meng and Dehong Ji, On some new nonlinear discrete inequalities and their applications, J. Comput. Appl. Math. 208, 2 (2007), 425-433. 
[12] D. R. ANDERSON, Nonlinear dynamic integral inequalities in two independent variables on time scale pairs, Advances in Dynamical Systems and Applications 3, 1 (2008), 1-13.

[13] W. N. LI, Nonlinear integral inequalities in two independent variables on time scales, Advances in Difference Equations, Volume 2011, Article ID 283926, 11 pages. 